OPEN ACCESS

Edited by: David Dockrell, University of Edinburgh, United Kingdom

Reviewed by:

Susu M. Zughaier, Emory University, United States Jonathan Thomas, University of Bolton, United Kingdom

*Correspondence:

Harlan P. Jones harlan.jones@unthsc.edu

Received: 16 January 2017 Accepted: 02 June 2017

Published: 22 June 2017

Citation: Ngo Ndjom CG, Kantor LV and Jones HP (2017) CRH Affects the

Phenotypic Expression of Sepsis-Associated Virulence Factors by Streptococcus pneumoniae

Serotype 1 In vitro.

Front. Cell. Infect. Microbiol. 7:263. doi: $10.3389 /$ fcimb.2017.00263

\section{CRH Affects the Phenotypic Expression of Sepsis-Associated Virulence Factors by Streptococcus pneumoniae Serotype 1 In vitro}

\author{
Colette G. Ngo Ndjom ${ }^{1}$, Lindsay V. Kantor ${ }^{2}$ and Harlan P. Jones ${ }^{1 *}$ \\ ${ }^{1}$ Department of Molecular and Medical Genetics, University of North Texas Health Science Center, Fort Worth, TX, United \\ States, ${ }^{2}$ Graduate School of Biomedical Sciences, University of North Texas Health Science Center, Fort Worth, TX, United \\ States
}

Sepsis is a life-threatening health condition caused by infectious pathogens of the respiratory tract, and accounts for $28-50 \%$ of annual deaths in the US alone. Current treatment regimen advocates the use of corticosteroids as adjunct treatment with antibiotics, for their broad inhibitory effect on the activity and production of pro-inflammatory mediators. However, despite their use, corticosteroids have not proven to be able to reverse the death incidence among septic patients. We have previously demonstrated the potential for neuroendocrine factors to directly influence Streptococcus pneumoniae virulence, which may in turn mediate disease outcome leading to sepsis and septic shock. The current study investigated the role of Corticotropin-releasing hormone $(\mathrm{CRH})$ in mediating key markers of pneumococcal virulence as important phenotypic determinants of sepsis and septic shock risks. In vitro cultures of serotype 1 pneumococcal strain with $\mathrm{CRH}$ promoted growth rate, increased capsule thickness and penicillin resistance, as well as induced pneumolysin gene expression. These results thus provide significant insights of $\mathrm{CRH}$-pathogen interactions useful in understanding the underlying mechanisms of neuroendocrine factor's role in the onset of community acquired pneumonias (CAP), sepsis and septic shock.

Keywords: Streptococcus pneumoniae, serotypes, corticotropin releasing hormone, sepsis virulence, phenotype

\section{INTRODUCTION}

Sepsis is a life-threatening health condition caused by infectious pathogens that may be acquired through communal contact and in hospital settings (Page et al., 2015). Disease pathogenesis is defined by breech of localized respiratory infection which precipitates into an uncontrolled systemic activation of multiple cellular immune and inflammatory pathways (Russell, 2006; Boomer et al., 2011). In cases of severe disease, conditions can manifest, involving hypotension and organ dysfunction, at which point it is referred to as septic shock. In the United States alone, $28-50 \%$ of sepsis patients die annually (Hall et al., 2011), exceeding the number of total deaths from prostate cancer, breast cancer, and AIDS (Wood and Angus, 2004). Furthermore, intensive care unit (ICU) patients are at higher risk of developing or being treated for sepsis (Martin, 2012), costing an average of $\$ 1,878$ per diem for state/local government hospitals and $\$ 2,289$ per diem for non-profit hospitals (Rappleye, 2015). 
Administration of corticosteroids is a common treatment of sepsis due to its broad inhibitory effect on the activity and production of pro-inflammatory mediators including cytokines, chemokines, eicosanoids, bradykinin, and activator protein-1 (Prigent et al., 2004). Yet, despite its ability to counteract overt inflammatory responses and restore cardiovascular homeostasis and organ function (Annane, 2011), the increase in the number of deaths raises questions regarding its clinical benefit. For example, analyses of randomized trials have suggested that administration of low-to-moderate doses of corticosteroids can improve survival (Annane et al., 2009; Minneci et al., 2009; Moran et al., 2010); whereas other meta-analyzes have demonstrated that corticosteroid regimens were not beneficial in sepsis and septic shock (Minneci et al., 2009; Sligl et al., 2009). Specifically, analysis of a 2005 clinical trial found that short course administration of corticosteroids did not reverse the mortality rates from sepsis, and in some instances increased the incidence of nosocomial infections, as well as of organ dysfunction (Beutz and Abraham, 2005). More recently, a metaanalysis of 35 randomized clinical trials evaluating steroids on sepsis patients did not yield a statistically significant beneficial effect of the use of corticosteroids in the treatment of sepsis (Volbeda et al., 2015). A deficiency in clear-cut evidence supporting or negating the benefits of corticosteroids in the treatment of sepsis highlights the complexity of this condition, and warrants a better understanding of the mechanisms of action.

The respiratory tract is the source of sepsis in $40-60 \%$ of patients (Nasa et al., 2012; Riyaz et al., 2014). Streptococcus pneumoniae (S. pneumoniae) is a common respiratory pathogen responsible for most community acquired pneumonias (CAP) cases worldwide (Lynch and Martinez, 2002). It is also a major cause of nosocomial associated sepsis mortality (Hifumi et al., 2016). Whereas restricted inflammatory immune responses of the respiratory tract are beneficial, excessive activation may elicit systemic manifestations of sepsis (Chen et al., 2011; Bosmann and Ward, 2013). Host protection against sepsis is influenced by endogenous glucocorticoid activity (e.g., cortisol release) controlled by the hypothalamic-pituitaryadrenal axis (HPA), that maintains homeostatic regulation of cellular immune and inflammatory responses (Wilson et al., 1998). However, a loss or deficiencies in HPA-mediated responses do occur (Annane, 2016), resulting in disruptions in normal adrenal axis functioning. This may cause hyper- or hypoactivation of the immune response against $S$. pneumoniae. Uncontrolled inflammatory responses have been shown to be critical determinants of sepsis and septic shock among patients diagnosed with community-acquired and nosocomial-associated S. pneumoniae (Sam et al., 2004; den Brinker et al., 2005).

The prognostic value of cortisol levels has been reported in sepsis and other critical illnesses (Annane et al., 2008) in correlation with the status of cellular immune and inflammatory mediators (Marik and Zaloga, 2002). In recent years, however, emphasis has shifted from determining the cross-talk between the neuroendocrine and immune systems to defining pathogens' direct response to neuroendocrine factors (Butts and Sternberg, 2008; ThyagaRajan and Priyanka, 2012; Procaccini et al., 2014). Corticotropin Releasing Hormone (CRH) is a 41 -amino acid neuropeptide secreted from the HPA, and stimulates the release of adrenal cortisol in response to infection and other stressors (Nezi et al., 2015). CRH is expressed in peripheral tissues (e.g., lung) and by immune cell populations, and has been shown to impact inflammatory disease (Crofford et al., 1992; van Tol et al., 1996; Benou et al., 2005; Kokkotou et al., 2006; Kalantaridou et al., 2007). In support, we have previously demonstrated a role for peripheral $\mathrm{CRH}$ in manipulating immune and inflammatory responses against $S$. pneumoniae respiratory infection (Gonzales et al., 2008; Kim et al., 2011). Our findings demonstrated an association between $\mathrm{CRH}$ expression in the lungs of mice with severe pneumonia and increased lung and systemic disease (Gonzales et al., 2008). We also found that pre-exposing $S$. pneumoniae to $\mathrm{CRH}$ increased bacterial counts in the lung. Furthermore, direct exposure to $\mathrm{CRH}$ resulted in increased bacterial growth, and Pneumococcal-associated virulence factor A (pavA) gene expression (Ndjom and Jones, 2015). Collectively these results suggest a possible correlation between a bacterial pathogen's response to stress hormones (e.g., glucocorticoids) and the risk for developing sepsis and septic shock. In this study, we determined the role of CRH in mediating capsular phenotype and pneumolysin expression, as well as antibiotic sensitivity as key markers of pneumococcal virulence. The results from the current study provide significant insights of $\mathrm{CRH}$-pathogen interactions useful in understanding the underlying mechanisms of neuroendocrine factor's role in disease pathogenesis.

\section{MATERIALS AND METHODS}

\section{Bacterial Strain and Growth Conditions}

Streptococcus pneumoniae strain 6301, serotype 1 (ATCC, Manassas, VA, USA) was used in all experiments. Prior to use, S. pneumoniae was maintained in $30 \%$ glycerol frozen stock solutions and stored at $-80^{\circ} \mathrm{C}$. For inoculum preparation, $S$. pneumoniae was grown at $37^{\circ} \mathrm{C}, 5 \% \mathrm{CO}_{2}$ either on Blood Agar plates (TSA w/5\% Sheep Blood) (Life Technologies, Carlsbad, $\mathrm{CA}$ ) or in Brain Heart Infusion broth (BHI) (Sigma Aldrich, St. Louis, MO).

\section{Corticotropin-Releasing Hormone (CRH)}

Human/Rat recombinant CRH (Sigma Aldrich, St. Louis, MO) was used in all experiments. CRH stock solutions were stored at $-20^{\circ} \mathrm{C}$ in $20 \mu \mathrm{l}$ aliquots until use.

\section{Pneumococcal Growth Curve}

Streptococcus pneumoniae was grown overnight to achieve midlog phase cultures on Blood Agar plates (Life Technologies, Carlsbad, CA). Twenty-four hours later, bacteria were collected and diluted in BHI until an optical density (O.D.) of 0.2 was achieved. A series of triplicate tubes were prepared containing $1,950 \mu \mathrm{l}$ of BHI and $50 \mu \mathrm{l}$ of $S$. pneumoniae in the presence or absence of either $4.0 \times 10^{-4}$ or $8.0 \times 10^{-4} \mathrm{mM} / \mu$ l concentration of $\mathrm{CRH}$. The tubes were incubated at $37^{\circ} \mathrm{C}, 5 \% \mathrm{CO}_{2}$. Triplicate absorbance readings $\left(\mathrm{OD}_{600}\right)$ of bacterial cultures were taken every $30 \mathrm{~min}$. Absorbance readings were plotted against time to generate bacterial growth curves. 


\section{Capsular Staining of S. pneumoniae}

Streptococcus pneumoniae was stained for capsular visualization as previously described by Hughes and Smith (2007). Briefly, $50 \mu \mathrm{l}\left(1 \times 10^{5}\right.$ organisms $)$ of bacterial suspension taken from frozen stock was exposed to $\mathrm{CRH}$ vs. control (broth only) and grown in $1 \mathrm{~mL}$ of $\mathrm{BHI}$ for $5 \mathrm{~h}$, at $37^{\circ} \mathrm{C}$ and $5 \% \mathrm{CO}_{2}$. Microscopy slides were prepared with 2-3 $\mu$ l drops of Congo red solution (Carolina Biological, Burlington, NC) to which 6 $\mu l$ of bacterial suspension were mixed. Slides were air dried before being flooded with Maneval solution (Carolina Biological, Burlington, NC) for $1 \mathrm{~min}$. Stained slides were then gently rinsed off with deionized (DI) water, placed on absorbent paper and left to air dry. Slides were examined under oil immersion at 100X magnification. Capsular staining images were captured using Olympus AX70 Provis microscope (NY, USA). Capsular thickness was calculated as the difference between the total diameter of the bacterial cell from its outer membrane and the total distance in the diameter of the inner capsular membrane. Three independent measures were taken of three different bacterial cells per three individuals slides were averaged and expressed as the percent difference in the mean capsular thickness of organisms exposed to CRH compared to the mean capsular difference of control (untreated) organisms. Capsular diameters were determined using Adobe Photoshop CS6 software (Adobe, San Jose, CA).

\section{Quantitation of S. pneumoniae's Antibiotic Sensitivity}

Preparation of Antibiotic Serial Dilutions

Two hundred microliters of a $10,000 \mathrm{U} / \mathrm{mL}$ stock penicillin/streptomycin (Thermo Fisher Scientific Inc., Waltham, MA) solution were added to the first well (Row A) of a 96-well microplate, in triplicates for both the $\mathrm{CRH}$ and non-CRH groups (total of six wells). One hindered microliter of Mueller-Hinton broth (Sigma Aldrich, St. Louis, MO) were added to all the remaining wells of each row. A serial dilution of the concentrated antibiotic cocktail was performed in Mueller-Hinton broth, resulting in 10 different antibiotic concentrations $(2,000,1,000$, $500,225,125,62.5,31.25,15.62,7.81$, and 3.9 U/well). Plates were then incubated at $35^{\circ} \mathrm{C}$ for $24 \mathrm{~h}$ for evaporation purposes before being used in the Minimum Inhibitory Concentration (MIC) assay.

\section{MIC Assay}

Streptococcus pneumoniae was grown overnight to achieve midlog phase cultures on Blood Agar plates (Life Technologies, Carlsbad, CA). Bacteria were collected and diluted in MuellerHinton broth (Sigma Aldrich, St. Louis, MO) until an optical density (O.D.) of 1 was achieved, representing a cell density of 5 $\times 10^{8}$ colony forming units $(\mathrm{CFU}) / \mathrm{mL}$. Twenty-five microliters of diluted bacteria were added onto the wells of a fresh 96-well (antibiotic free) microplate, representative of both $\mathrm{CRH}$-treated and $\mathrm{CRH}$-untreated groups. Twenty microliter of $\mathrm{CRH}(4.0 \times$ $10^{-4} \mathrm{mM} / \mu \mathrm{l}$ ) were added to each well of the $\mathrm{CRH}$-treated group, followed by $200 \mu \mathrm{l}$ of Mueller-Hinton broth and Defibrinated Sheep Blood (Sigma Aldrich, St. Louis, MO) mixture. In the $\mathrm{CRH}$-untreated group, only the broth/blood mixture were added to the wells containing bacterial suspension. The control groups, free of antibiotic cocktail, also received bacterial suspension along with the broth/blood mixture $( \pm \mathrm{CRH})$. The plate was covered and incubated for $2 \mathrm{~h}$ at $37^{\circ} \mathrm{C}$ and $5 \% \mathrm{CO}_{2}$. Post-incubation, each well was transferred onto the dehydrated penicillin/streptomycin 96-well microplate. The plate was read using a Synergy 2 multi-modal microplate reader plate reader (BioTek, Winooski, VT) for time zero (T0) and incubated overnight at $37^{\circ} \mathrm{C}$ and $5 \% \mathrm{CO}_{2}$. The plate was again read $24 \mathrm{~h}$ post-incubation (T24). All measurements and experiments were performed in triplicates.

\section{Pneumolysin (Ply) mRNA Gene Expression by Quantitative Real-Time Polymerase Chain Reaction (qRT-PCR)}

\section{Bacterial RNA Extraction}

Streptococcus pneumoniae exposed to CRH vs. control (broth only) was collected $5 \mathrm{~h}$ after incubation in separate $3 \mathrm{ml}$ sterile conical tubes in $1 \mathrm{~mL}$ of sterile BHI broth. Bacterial suspensions were transferred into $1.5 \mathrm{~mL}$ Eppendorf centrifuge tubes and spun down at $14,000 \mathrm{~g}$ for $1 \mathrm{~min}$. The pellets were then stored in $100 \mu \mathrm{l}$ of RNAlater solution for subsequent RNA extraction. RNA extraction from bacterial cells was performed using a RiboPure RNA Purification Kit (Life Technologies, Carlsbad, CA).

\section{Reverse Transcription and Quantitative Real-Time RT-PCR}

A starting Total RNA concentration of $1 \mu \mathrm{g}$ per reaction and MLV (Molony murine leukemia virus) reverse transcriptase (Promega Corp., Madison, WI) were used to generate bacterial cDNA. Post-cDNA synthesis, real-time PCR was performed using SYBR green-based amplification techniques. Briefly, PCR was performed in $20 \mu \mathrm{l}$ reaction volume using the StepOne system (Applied Biosystems Inc., Foster City, CA). The expression of the housekeeping gene $16 \mathrm{~s}$ rRNA was used as an internal control to normalize target gene expression between samples. $\Delta \Delta^{\mathrm{CT}}=\Delta^{\mathrm{CT}}$ (target gene) $-\Delta^{\mathrm{CT}}$ (16 s rRNA) formula was used to calculate gene expression in bacterial cells of pneumolysin (Ply) gene. Data was calculated by subtracting $\Delta \Delta^{\mathrm{CT}}$ of control group from the CRH-treated group for each target gene. Data was expressed as the fold difference in Ply mRNA expression, by normalizing the expression of untreated Ply as 1 . Selected targets and housekeeping gene primer sets; Ply, and 16 s rRNA were purchased from Life Technologies, Carlsbad, CA (Table 1).

\section{Statistical Analysis}

Statistical analysis was performed using GraphPad Prism Version 6.0 (GraphPad Software, San Diego, USA). For multiexperimental group analysis, data were subjected to one-way and two-way ANOVA (analysis of variance) followed by post-hoc tests (Newman-Keuls and Bonfferoni) for group differences. All data are expressed as means \pm standard error of mean (SEM). A $p \leq$ 0.05 was considered significant. 
TABLE 1 | List of primer sequences and target gene.

\begin{tabular}{lc}
\hline \multicolumn{1}{c}{ Sequence } \\
\hline HOUSE-KEEPING GENE Rogers et al., 2007 \\
16 S rRNA-Forward $\left(5^{\prime}-3^{\prime}\right)$ & TGAGTTAACCGTAAGGAGCCA \\
16S rRNA-Reverse $\left(3^{\prime}-5^{\prime}\right)$ & TCACCCCAATCATCTATCCCA \\
PLY-2 (PNEUMOCOCCAL PNEUMOLYSIN 2) Cope et al., 2011 \\
Forward $\left(5^{\prime}-3^{\prime}\right)$ & CTACCCGATGAGTTGTTGTT \\
Reverse $\left(3^{\prime}-5^{\prime}\right)$ & TCCAGGATAGAGGCGACT \\
\hline
\end{tabular}

\section{RESULTS}

\section{Introducing CRH during Log-Phase Promotes Pneumococcal Growth}

The current study sought to determine whether growth could be influenced during $S$. pneumoniae's highest rate of growth (e.g., log-phase). As shown in Figure 1, introducing CRH $\left(8 \times 10^{-4}\right.$ $\mathrm{mM} / \mu \mathrm{l}$ ) during log phase resulted in a significant increase in bacterial growth compared to exposure of $\mathrm{CRH}$ during lag phase growth. The growth curve was carried out over a $9 \mathrm{~h}$ period with now differences in growth observed beyond the 180-min point. Figure 1 shows the effect of $\mathrm{CRH}$ as observed up to $180 \mathrm{~min}$. These findings demonstrate a dependency on the growth phase of $S$. pneumoniae to be influenced by CRH.

\section{CRH Increases Capsular Formation}

Capsule formation is a key virulence factor of $S$. pneumoniae (AlonsoDeVelasco et al., 1995) related to bacterial growth, attachment, biofilm integrity, and antibiotic resistance. It is also the source of many membrane bound and secreted proteolytic components owing to its pathogenesis (Wilson et al., 2002). The percent difference in capsule thickness was plotted for $\mathrm{CRH}$ treated groups against control (without $\mathrm{CRH}$ exposure). $\mathrm{CRH}$ exposure resulted in a significant increase in capsule thickness compared control (Figure 2). The increase in capsule formation in response to $\mathrm{CRH}$ was found to have a similar effect on three additional serotypes 3, 19A, and 23F (see Supplementary Figure 1).

\section{CRH Increases Antibiotic Resistance}

Capsule morphology influences the sensitivity to antibiotic targets. Given the effect by CRH on capsular thickness, studies were performed to determine whether $\mathrm{CRH}$ could have an impact on antibiotic resistance in S. pneumoniae. As such, $\mathrm{CRH}$ was introduced to bacterial cultures followed by incubation with different concentrations of Penicillin/Streptomycin (P/S) cocktail. CRH exposed S. pneumoniae showed a greater than three-fold resistance to $\mathrm{P} / \mathrm{S}$ cocktail when compared to the untreated bacterial group (Figure 3).

\section{CRH Increases Pneumolysin (Ply) mRNA Gene Expression}

As a non-membrane associated peptide, pneumolysin is prominently associated with disease pathogenesis of $S$. pneumoniae. Previous studies suggest that pneumolysin can influence immune and inflammatory responses contributing to sepsis and septic shock (Malley et al., 2003; Alhamdi et al., 2015). Our results show that $\mathrm{CRH}$ exposure significantly increases Ply mRNA gene expression at $3 \mathrm{~h}$ (Figure 4).

\section{DISCUSSION}

HPA-derived $\mathrm{CRH}$ mediates immune and inflammatory responses by control of cortisol (corticosterone in mice) release from the adrenals, which target glucocorticoid receptors expressed on peripheral tissues and immune cells. This causes a down-regulation of signaling pathways that suppress immune and inflammatory proteins and secreted factors (Silverman et al., 2005; Nezi et al., 2015). In addition, studies have shown that $\mathrm{CRH}$ can control immune and inflammatory responses directly through peripheral $\mathrm{CRH}$ expression and cognate $\mathrm{CRH}$ receptor ligation in peripheral tissues (Mastorakos et al., 2006; Nezi et al., 2015). Little is known however, regarding a bacterial species' response to $\mathrm{CRH}$ and other neuroendocrine factors as determinants of its virulence and pathogenicity. In previous studies, we were the first to demonstrate, to our knowledge, that $\mathrm{CRH}$ could directly impact $S$. pneumoniae's growth and in vivo pathogenesis (Ndjom and Jones, 2015). The results of the current study indicate that $\mathrm{CRH}$ potentiates morphological, genetic and functional properties vital to $S$. pneumoniae's virulence.

The transition from asymptomatic carriage to a pathogenic phenotype is dependent on a complex array of biochemical environmental cues that can influence the growth characteristics of S. pneumoniae (Cortes et al., 2015). Previous studies have demonstrated that changes in environments can modulate numerous proteins and carbohydrates that modify cell attachment, colonization and invasion that dictate biofilm formation and persistence in host (Allegrucci et al., 2006; Sanchez et al., 2011; Allan et al., 2014). In the current study, in vitro $\mathrm{CRH}$ exposure was found to accentuate growth when introduced during log phase. In contrast, CRH exposure during lag phase did not impact bacterial growth compared to control. We believe these results suggest the potential for $\mathrm{CRH}$ to modulate metabolic responses influential in the transition of growth status. In support, Raymond et al, elucidated by protein profiling, putative gene targets responsible for nascent phasic growth of $S$. pneumoniae observed during lag phase (Allan et al., 2014). Understanding however, that growth and biofilm formation involves a complex multistep process requires further study.

The current licensed 23-valent polysaccharide pneumococcal vaccine contains 23 purified capsular polysaccharide antigens of $S$. pneumoniae serotypes including serotype 1 used in this study (Jedrzejas, 2001). Proteins and enzymes embedded on the surface of $S$. pneumoniae have been shown to significantly contribute to its pathogenesis involving direct contact with host tissues, biofilm formation, and in concealing bacterial-associated molecules from host defense mechanisms (AlonsoDeVelasco et al., 1995; Mitchell and Mitchell, 2010). We found that CRH induced a significant increase in capsule thickness, indicating that this neuropeptide could potentially impact pneumococcal 


\section{$4.0 \times 10^{-4} \mathrm{mM} / \mathrm{ul}$}

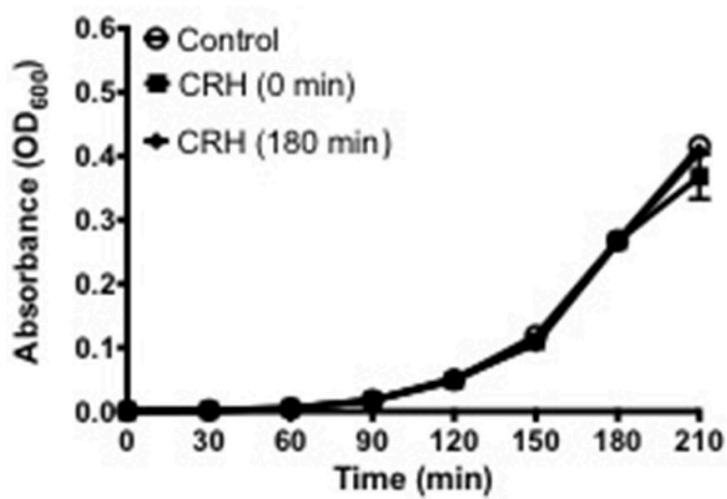

$8.0 \times 10^{-4} \mathrm{mM} / \mathrm{ul}$

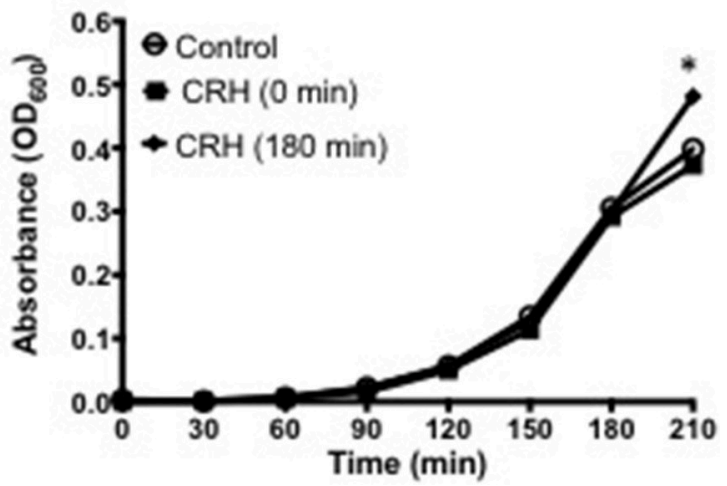

FIGURE 1 | $\mathrm{CRH}$ promotes pneumococcal growth at log-phase. Growth curve analysis was performed on Serotype 1 pneumococcal strain in the presence or absence of $\mathrm{CRH}\left(4.0 \times 10^{-4}\right.$ and $\left.8.0 \times 10^{-4} \mathrm{mM} / \mu \mathrm{l}\right)$. Data represents mean $(n=3) \pm$ standard deviation between $\mathrm{CRH}$ and control. Asterisks $\left({ }^{*}\right)$ indicate significant $(P \leq 0.05)$ differences between experimental and control groups.

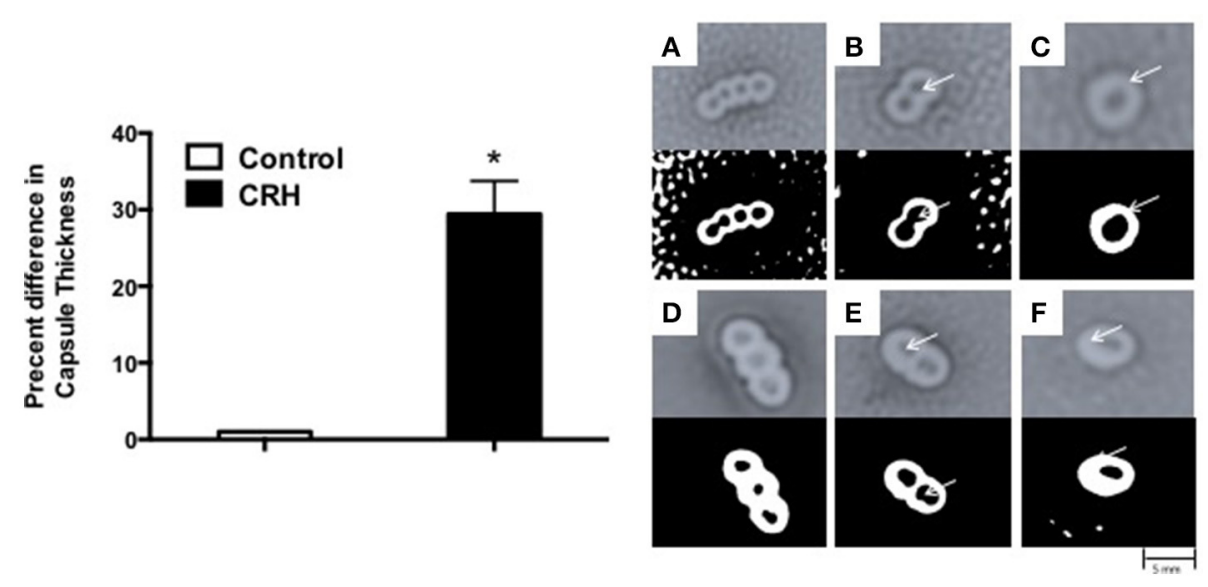

FIGURE 2 | Capsular thickness is increased by $\mathrm{CRH}$. Serotype 1 pneumococcal strain ( $10^{8}$ organisms) was grown in the presence or absence of $\mathrm{CRH}\left(4.0 \times 10^{-4}\right.$ $\mathrm{mM} / \mu \mathrm{l})$ for $5 \mathrm{~h}$. Capsular thickness was determined by calculating the absolute difference between total diameter of outer and inner capsular membranes. Bars represent the mean $(n=9) \pm$ standard deviation in the percent difference in capsular diameters of $\mathrm{CRH}$-treated organisms compared to control. Asterisks $\left(^{\star}\right)$ indicate significant $(P \leq 0.05)$ differences between experimental and control groups (Left). 100X magnified images of untreated (A-C) and CRH-treated (D-F) S. pneumoniae are shown in right panel. Lower panels represent corresponding high contrast color images highlighting capsule and diplonuclei denoted by arrows.

morphological phenotypes. Similarly, serotypes 3, 19A, and 23F were also found to increase capsule size (Supplementary Figure 1). Environmental factors impact capsule phenotype that can dictate pneumococcal transition from carriage within the nasal passages to a more motile invasive phenotype (Selinger et al., 1979; Kim and Weiser, 1998; Weiser et al., 2001; Hammerschmidt et al., 2005). Previous studies have characterized thinner capsular phenotypes to be associated with early colonization. In fact, the more sessile phenotypes resemble a thicker capsule present during invasive disease (Kim and Weiser, 1998; Kim et al., 1999). Furthermore, Lee et al. (1991) and Weinberger et al. (2009) reported that increased capsular thickness was advantageous to $S$. pneumoniae, as it allows the bacteria to evade phagocytosis by immune cells and thus, increase its carriage within the host environment. While this is the first study to examine capsule formation in response to $\mathrm{CRH}$, previous studies have demonstrated catecholamineeffects on bacterial biofilm formation. Specifically, Sandrini et al. showed that norepinephrine (NE) exposure had no effect on capsule formation compared to bacterial growth, but increased pneumococcal attachment (Sandrini et al., 2014). In addition, Marks et al., found that NE induced the release of bacteria from biofilms (Marks et al., 2013). Our finding that CRH increased capsule growth is consistent with potentiating the invasive phenotype of serotype 1 . In that other serotypes tested responded similarly to $\mathrm{CRH}$ in terms of capsular formation suggest $\mathrm{CRH}$ could be a global regulator of capsular structure and therefore relevant to pneumococcal pathogenicity. The capsular 


\section{No CRH}

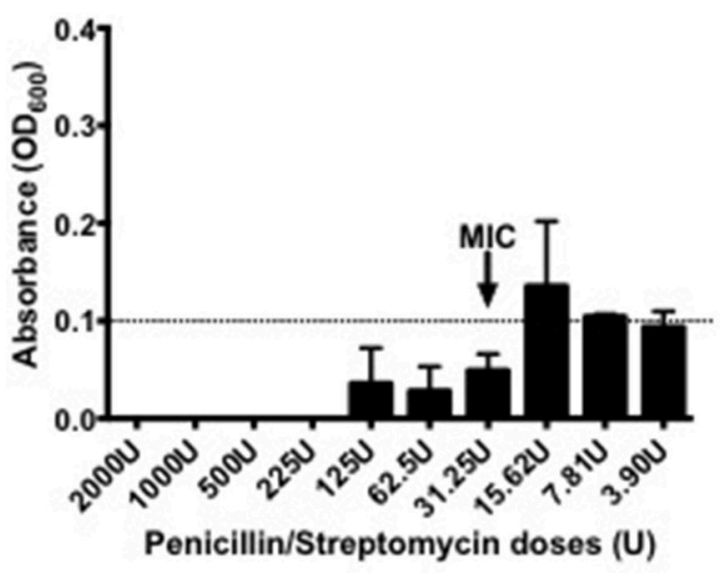

CRH

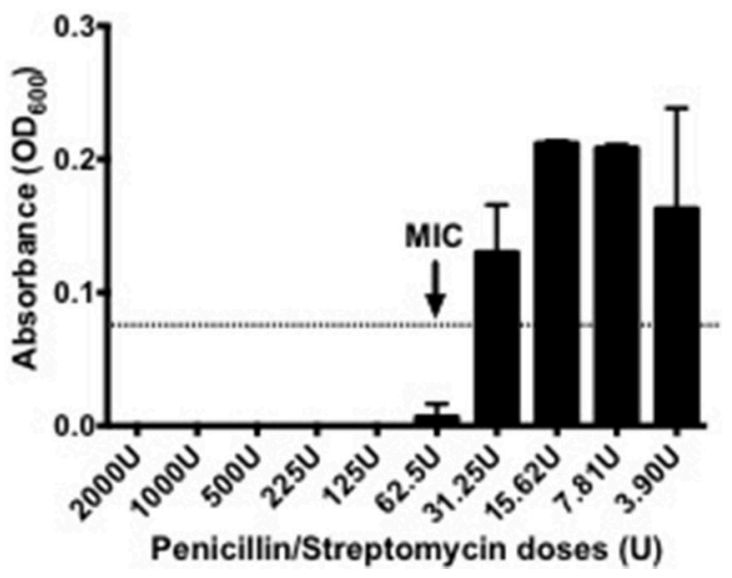

FIGURE 3 | $\mathrm{CRH}$ increases antibiotic resistance. Serotype 1 pneumococcal strain were incubated for $2 \mathrm{~h}$ in the presence or absence of $\mathrm{CRH}\left(4.0 \times 10^{-4} \mathrm{mM} / \mu \mathrm{l}\right)$, and subsequently exposed overnight to various penicillin/streptomycin concentrations (2,000, 1,000, 500, 225, 125, 62.5, 31.25, 15.62, 7.81, and 3.9 U/well). Data represents one of three independent experiments performed in triplicate. Arrow indicates the minimal inhibitory concentration (MIC).

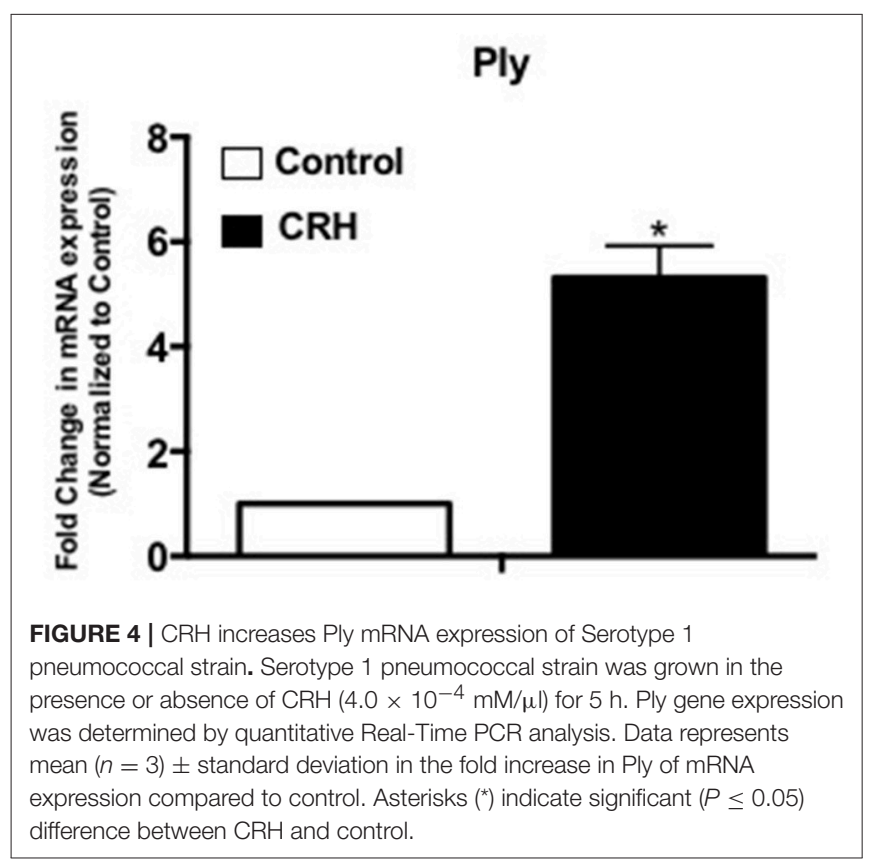

polysaccharide of $S$. pneumoniae mainly consists of repeating oligosaccharide units composed of two to eight monosaccharides linked by glycosidic bonds in which capsular diversity is generated (van Selm et al., 2003). To date, the genes regulating capsular synthesis for most serotypes including serotype 1 have been sequenced (van Selm et al., 2003). Such information will benefit how $\mathrm{CRH}$ may influence the genetic regulatory networks encoding the capsule biosynthesis pathways.

Although antimicrobial agents such as penicillin have been proven effective in reducing the risk from pneumococcal disease, resistant strains continue to increase in the United
States and worldwide (Hackel et al., 2013; Musher, 2016). Studies have documented in some areas as much as $35 \%$ of pneumococcal isolates are resistant to penicillin (Arnold et al., 1996; Schrag et al., 2004; Low, 2005). We therefore determined the potential influence of CRH on S. pneumoniae's sensitivity to penicillin/streptomycin. Serotype 1 exposed to $\mathrm{CRH}$ resulted in greater than two-fold resistance to penicillin/streptomycin defined by the minimal inhibitory concentration. In support, a previous study by Severin et al., reported that genetic elements related to penicillin binding-proteins may produce a reduction in penicillin affinity by genetic transformation (Severin et al., 1996). It is worth noting that all tested serotypes revealed the highest percent increase in capsular thickness compared to nonCRH exposed serotypes (Supplementary Figure 1). Thus, one might expect that $\mathrm{CRH}$ plays a role in polysaccharide structure by increased polymerization of repeating oligosaccharide units. Furthermore, an increased high molecular capsular mass structure could provide added protection against penicillin targets. This and other potential mechanisms of antibiotic resistance dictated by $\mathrm{CRH}$ and other neuroendocrine factors may prove significant given the ever-increasing antibiotic resistance among invasive pneumococcal serotypes.

The discovery of pneumolysin (Ply) and other pneumococcal peptides, has led to an insurgence of novel virulence factors useful in vaccine development (Briles et al., 1997; Jedrzejas, 2001; Lin et al., 2015). Ply is a non-surface bound 53-kDA protein that penetrates the physical defense of the host tissue barriers (Hirst et al., 2004). Ply is a cytotoxic enzyme which mainly disrupts host ciliary function and tight junctions of bronchial epithelia that impairs mucus clearance in the lower respiratory airways (Rayner et al., 1995). We found CRH to increase Ply mRNA expression, indicating a non-membrane associated response by S. pneumoniae to CRH. In addition, Ply mRNA expression varied among serotypes 3,19A, and 23F. Whereas serotypes 3 and 
19A Ply expression was decreased in response to CRH, 23F Ply mRNA expression was significantly increased (Supplementary Figure 2). Ply is released in response to activation of surface autolysins. These enzymes degrade the peptidoglycan backbone of pneumococcus and are believed to be involved in cell growth turnover (Rogers et al., 1980). Interestingly, while CRH promoted capsular size, the increase in Ply gene expression suggest an inverse relationship between the activation of autolysins that would negatively influence cell wall growth; thus, contradicting the observed increase in Ply mRNA expression. Nevertheless, the induction of Ply in response to CRH suggest a mechanism through which pneumococcus may sense stress that elicits the induction of virulence gene expression of non-membrane bound proteins. Future studies that determine the temporal as well as serotype specificity of $\mathrm{CRH}$-induced Ply protein secretion in relation to capsule and autolysin expression would confirm such direct or dichotomous relationships. Moreover, an in-depth study of the effects of CRH on the large class of non-membrane virulence factors will be important to fully understand its role in the pathophysiology of S. pneumoniae.

Much of the reports pertaining to neuroendocrine factors' role in S. pneumoniae virulence and pathogenicity have focused on catecholaminergic responses (Won and Ross, 1975; Gonzales et al., 2013; Sandrini et al., 2014). Yet, little is known regarding how glucocorticoids directly impact bacterial pathogenicity (Christ-Crain et al., 2007; Verbrugghe et al., 2011; Simard et al., 2014; Declercq et al., 2016). We have previously demonstrated a correlation between CRH exposure and increased disease severity in vivo. In this study, we begin to delineate direct mechanisms responsible for CRH's effect on key functional hallmarks of pneumococcal virulence. S. pneumoniae causes a variety of diseases among which, sepsis and septic shock remain a major health concern in the U.S and worldwide. Adequate treatment is becoming more complicated due to the emergence of increased resistance to commonly used antibiotics (Charpentier and Tuomanen, 2000). In addition, control of immunopathologies caused by aberrant immune and inflammatory responses remains a major mortality risk. Due to the current controversy surrounding the use of glucocorticoid administration, an in depth understanding of the implications of bacterial species' response to CRH and other glucocorticoids is warranted. We anticipate that defining pathways through which $\mathrm{CRH}$ regulates $S$. pneumoniae's physiology could reveal putative therapeutic targets as novel and alternative approaches to control adverse inflammatory responses. An increased knowledge of

\section{REFERENCES}

Alhamdi, Y., Neill, D. R., Abrams, S. T., Malak, H. A., Yahya, R., BarrettJolley, R., et al. (2015). Circulating pneumolysin is a potent inducer of cardiac injury during pneumococcal infection. PLoS Pathog. 11:e1004836. doi: 10.1371/journal.ppat.1004836

Allan, R. N., Skipp, P., Jefferies, J., Clarke, S. C., Faust, S. N., HallStoodley, L., et al. (2014). Pronounced metabolic changes in adaptation to biofilm growth by Streptococcus pneumoniae. PLoS ONE 9:e107015. doi: 10.1371/journal.pone.0107015

Allegrucci, M., Hu, F. Z., Shen, K., Hayes, J., Ehrlich, G. D., Post, J. C., et al. (2006). Phenotypic characterization of Streptococcus pneumoniae
$\mathrm{CRH}$ interaction with bacterial pathogens in the present of antimicrobial agents will benefit the potential for novel antibiotics. In addition, information regarding CRH's role in mediation of membrane and non-membrane bound peptides could reveal novel target as vaccine candidates. Furthermore, studies defining the mechanisms by which $S$. pneumoniae recognizes and responds to CRH will help advance the field of bacterio-endocrinology. Resolving these points will have a broader impact in the prevention and treatment of infectious disease.

\section{AUTHOR CONTRIBUTIONS}

$\mathrm{HJ}$ : as corresponding author directed and reviewed the design, execution, and data interpretation of all studies and affirmed the final draft of this paper for submission. $\mathrm{CN}$ : as lead author, developed and conducted, interpreted, and produced in its current version all of the studies within this paper and produced the final written version of this paper with advise from her co-authors. LK: as co-author assisted $\mathrm{CN}$ in the development and execution of the gene expression study and contributed to the interpretation of data findings relevant to the study.

\section{FUNDING}

This work was supported by intramural funding provided by the Institute of Molecular Medicine, The University of North Texas Health Science Center, Fort Worth, Texas.

\section{ACKNOWLEDGMENTS}

We would like to thank the laboratory of Drs. Allen, Basha, and Sun for the use of their research core facilities. We would also like to thank Mark Pulse, M.S. for his help in establishing a methodology for the MIC assay. The authors would like to acknowledge Ms. Mira Bakine and Mr. Ted Richardson for their assistance in the execution of the studies communicated in this research.

\section{SUPPLEMENTARY MATERIAL}

The Supplementary Material for this article can be found online at: http://journal.frontiersin.org/article/10.3389/fcimb. 2017.00263/full\#supplementary-material

biofilm development. J. Bacteriol. 188, 2325-2335. doi: 10.1128/JB.188.7.23 25-2335.2006

AlonsoDeVelasco, E., Verheul, A. F., Verhoef, J., and Snippe, H. (1995). Streptococcus pneumoniae: virulence factors, pathogenesis, and vaccines. Microbiol. Rev. 59, 591-603.

Annane, D. (2011). Corticosteroids for severe sepsis: an evidence-based guide for physicians. Ann. Intensive Care 1:7. doi: 10.1186/2110-5820-1-7

Annane, D. (2016). The role of ACTH and corticosteroids for sepsis and septic shock: an update. Front. Endocrinol. 7:70. doi: 10.3389/fendo.2016. 00070

Annane, D., Bellissant, E., Bollaert, P. E., Briegel, J., Confalonieri, M., De Gaudio, R., et al. (2009). Corticosteroids in the treatment of severe sepsis 
and septic shock in adults: a systematic review. JAMA 301, 2362-2375. doi: 10.1001/jama.2009.815

Annane, D., Umberto Meduri, G., and Marik, P. (2008). Critical illnessrelated corticosteroid insufficiency and community-acquired pneumonia: back to the future! Eur. Respir. J. 31, 1150-1152. doi: 10.1183/09031936.000 40908

Arnold, K. E., Leggiadro, R. J., Breiman, R. F., Lipman, H. B., Schwartz, B., Appleton, M. A., et al. (1996). Risk factors for carriage of drug-resistant Streptococcus pneumoniae among children in Memphis, Tennessee. J. Pediatr. 128, 757-764. doi: 10.1016/S0022-3476(96)70326-8

Benou, C., Wang, Y., Imitola, J., VanVlerken, L., Chandras, C., Karalis, K. P., et al. (2005). Corticotropin-releasing hormone contributes to the peripheral inflammatory response in experimental autoimmune encephalomyelitis. J. Immunol. 174, 5407-5413. doi: 10.4049/jimmunol.174.9.5407

Beutz, M. A., and Abraham, E. (2005). Community-acquired pneumonia and sepsis. Clin. Chest Med. 26, 19-28. doi: 10.1016/j.ccm.2004.10.015

Boomer, J. S., To, K., Chang, K. C., Takasu, O., Osborne, D. F., Walton, A. H., et al. (2011). Immunosuppression in patients who die of sepsis and multiple organ failure. JAMA 306, 2594-2605. doi: 10.1001/jama.2011.1829

Bosmann, M., and Ward, P. A. (2013). The inflammatory response in sepsis. Trends Immunol. 34, 129-136. doi: 10.1016/j.it.2012.09.004

Briles, D. E., Hollingshead, S. K., Swiatlo, E., Brooks-Walter, A., Szalai, A., Virolainen, A., et al. (1997). PspA and PspC: their potential for use as pneumococcal vaccines. Microb. Drug Resist. 3, 401-408. doi: 10.1089/mdr.1997.3.401

Butts, C. L., and Sternberg, E. M. (2008). Neuroendocrine factors alter host defense by modulating immune function. Cell. Immunol. 252, 7-15. doi: 10.1016/j.cellimm.2007.09.009

Charpentier, E., and Tuomanen, E. (2000). Mechanisms of antibiotic resistance and tolerance in Streptococcus pneumoniae. Microbes Infect. 2, 1855-1864. doi: 10.1016/S1286-4579(00)01345-9

Chen, X.-H., Yin, Y.-J., and Zhang, J.-X. (2011). Sepsis and immune response. World J. Emer. Med. 2, 88-92. doi: 10.5847/wjem.j.1920-8642.2011.02.002

Christ-Crain, M., Stolz, D., Jutla, S., Couppis, O., Muller, C., Bingisser, R., et al. (2007). Free and total cortisol levels as predictors of severity and outcome in community-acquired pneumonia. Am. J. Respir. Crit. Care Med. 176, 913-920. doi: 10.1164/rccm.200702-307OC

Cope, E. K., Goldstein-Daruech, N., Kofonow, J. M., Christensen, L., McDermott, B., Monroy, F., et al. (2011). Regulation of virulence gene expression resulting from Streptococcus pneumoniae and nontypeable Haemophilus influenzae interactions in chronic disease. PLOS ONE 6:e28523. doi: 10.1371/journal.pone.0028523

Cortes, P. R., Piñas, G. E., Cian, M. B., Yandar, N., and Echenique, J. (2015). Stresstriggered signaling affecting survival or suicide of Streptococcus pneumoniae. Int. J. Med. Microbiol. 305, 157-169. doi: 10.1016/j.ijmm.2014.12.002

Crofford, L. J., Sano, H., Karalis, K., Webster, E. L., Goldmuntz, E. A., Chrousos, G. P., et al. (1992). Local secretion of corticotropin-releasing hormone in the joints of Lewis rats with inflammatory arthritis. J. Clin. Invest. 90, 2555-2564. doi: 10.1172/JCI116150

Declercq, A. M., Aerts, J., Ampe, B., Haesebrouck, F., De Saeger, S., and Decostere, A. (2016). Cortisol directly impacts Flavobacterium columnare in vitro growth characteristics. Vet. Res. 47, 84. doi: 10.1186/s13567-016-0370-9

den Brinker, M., Joosten, K. F., Liem, O., de Jong, F. H., Hop, W. C., Hazelzet, J. A., et al. (2005). Adrenal insufficiency in meningococcal sepsis: bioavailable cortisol levels and impact of interleukin-6 levels and intubation with etomidate on adrenal function and mortality. J. Clin. Endocrinol. Metab. 90, 5110-5117. doi: $10.1210 /$ jc. $2005-1107$

Gonzales, X. F., Castillo-Rojas, G., Castillo-Rodal, A. I., Tuomanen, E., and LopezVidal, Y. (2013). Catecholamine norepinephrine diminishes lung epithelial cell adhesion of Streptococcus pneumoniae by binding iron. Microbiology 159(Pt 11), 2333-2341. doi: 10.1099/mic.0.065607-0

Gonzales, X. F., Deshmukh, A., Pulse, M., Johnson, K., and Jones, H. P. (2008). Stress-induced differences in primary and secondary resistance against bacterial sepsis corresponds with diverse corticotropin releasing hormone receptor expression by pulmonary CD11c+ MHC II+ and CD11c- MHC II+ APCs. Brain Behav. Immun. 22, 552-564. doi: 10.1016/j.bbi.2007.11.005

Hackel, M., Lascols, C., Bouchillon, S., Hilton, B., Morgenstern, D., and Purdy, J. (2013). Serotype prevalence and antibiotic resistance in Streptococcus pneumoniae clinical isolates among global populations. Vaccine 31, 4881-4887. doi: 10.1016/j.vaccine.2013.07.054

Hall, M. J., Williams, S. N., DeFrances, C. J., and Golosinskiy, A. (2011). Inpatient care for septicemia or sepsis: a challenge for patients and hospitals. NCHS Data Brief. Available online at: https://www.cdc.gov/nchs/data/databriefs/db62.htm

Hammerschmidt, S., Wolff, S., Hocke, A., Rosseau, S., Müller, E., and Rohde, M. (2005). Illustration of pneumococcal polysaccharide capsule during adherence and invasion of epithelial cells. Infect. Immun. 73, 4653-4667. doi: 10.1128/IAI.73.8.4653-4667.2005

Hifumi, T., Fujishima, S., Abe, T., Kiriu, N., Inoue, J., Kato, H., et al. (2016). Prognostic factors of Streptococcus pneumoniae infection in adults. Am. J. Emerg. Med. 34, 202-206. doi: 10.1016/j.ajem.2015.10.025

Hirst, R. A., Kadioglu, A., O'Callaghan, C., and Andrew, P. W. (2004). The role of pneumolysin in pneumococcal pneumonia and meningitis. Clin. Exp. Immunol. 138, 195-201. doi: 10.1111/j.1365-2249.2004.02611.x

Hughes, R. B., and Smith. A. C. (2007). Capsule Stain Protocols [Online]. ASM MicrobeLibrary. Available online at: http://www.asmscience.org/content/education/protocol/protocol.3041

Jedrzejas, M. J. (2001). Pneumococcal virulence factors: structure and function. Microbiol. Mol. Biol. Rev. 65, 187-207. doi: 10.1128/MMBR.65.2.187-207.2001

Kalantaridou, S., Makrigiannakis, A., Zoumakis, E., and Chrousos, G. P. (2007) Peripheral corticotropin-releasing hormone is produced in the immune and reproductive systems: actions, potential roles and clinical implications. Front. Biosci. 12, 572-580. doi: 10.2741/2083

Kim, B. J., Kayembe, K., Simecka, J. W., Pulse, M., and Jones, H. P. (2011). Corticotropin-releasing hormone receptor-1 and 2 activity produces divergent resistance against stress-induced pulmonary Streptococcus pneumoniae infection. J. Neuroimmunol. 237, 57-65. doi: 10.1016/j.jneuroim.2011.06.016

Kim, J. O., and Weiser, J. N. (1998). Association of intrastrain phase variation in quantity of capsular polysaccharide and teichoic acid with the virulence of Streptococcus pneumoniae. J. Infect. Dis. 177, 368-377. doi: 10.1086/514205

Kim, J. O., Romero-Steiner, S., Sørensen, U. B. S., Blom, J., Carvalho, M., Barnard, S., et al. (1999). Relationship between cell surface carbohydrates and intrastrain variation on opsonophagocytosis of Streptococcus pneumoniae. Infect. Immun. 67, 2327-2333.

Kokkotou, E., Torres, D., Moss, A. C., O’Brien, M., Grigoriadis, D. E., Karalis, K., et al. (2006). Corticotropin-releasing hormone receptor 2-deficient mice have reduced intestinal inflammatory responses. J. Immunol. 177, 3355-3361. doi: 10.4049/jimmunol.177.5.3355

Lee, C. J., Banks, S. D., and Li, J. P. (1991). Virulence, immunity, and vaccine related to Streptococcus pneumoniae. Crit. Rev. Microbiol. 18, 89-114. doi: 10.3109/10408419109113510

Lin, H., Peng, Y., Lin, Z., Zhang, S., and Guo, Y. (2015). Development of a conjugate vaccine against invasive pneumococcal disease based on capsular polysaccharides coupled with PspA/family 1 protein of Streptococcus pneumoniae. Microb. Pathog. 83-84, 35-40. doi: 10.1016/j.micpath.2015.04.006

Low, D. E. (2005). Changing trends in antimicrobial-resistant pneumococci: it's not all bad news. Clin. Infect. Dis. 41(Suppl. 4), S228-S233. doi: 10.1086/430782

Lynch, J. P., and Martinez, F. J. (2002). Clinical relevance of macrolide-resistant Streptococcus pneumoniae for community-acquired pneumonia. Clin. Infect. Dis. 34(Suppl. 1), S27-S46. doi: 10.1086/324527

Malley, R., Henneke, P., Morse, S. C., Cieslewicz, M. J., Lipsitch, M., Thompson, C. M., et al. (2003). Recognition of pneumolysin by Toll-like receptor 4 confers resistance to pneumococcal infection. Proc. Natl. Acad. Sci. U.S.A. 100, 1966-1971. doi: 10.1073/pnas.0435928100

Marik, P. E., and Zaloga, G. P. (2002). Adrenal insufficiency in the critically ill: a new look at an old problem. Chest 122, 1784-1796. doi: $10.1378 /$ chest.122.5.1784

Marks, L. R., Davidson, B. A., Knight, P. R., and Hakansson, A. P. (2013). Interkingdom signaling induces Streptococcus pneumoniae biofilm dispersion and transition from asymptomatic colonization to disease. mBio 4:e00438-13. doi: $10.1128 / \mathrm{mBio} .00438-13$

Martin, G. S. (2012). Sepsis, severe sepsis and septic shock: changes in incidence, pathogens and outcomes. Expert Rev. Anti Infect. Ther. 10, 701-706. doi: 10.1586/eri.12.50

Mastorakos, G., Karoutsou, E. I., and Mizamtsidi, M. (2006). Corticotropin releasing hormone and the immune/inflammatory response. Eur. J. Endocrinol. 155(Suppl. 1), S77-S84. doi: 10.1530/eje.1.02243 
Minneci, P. C., Deans, K. J., Eichacker, P. Q., and Natanson, C. (2009). The effects of steroids during sepsis depend on dose and severity of illness: an updated meta-analysis. Clin. Microbiol. Infect. 15, 308-318. doi: 10.1111/j.1469-0691.2009.02752.x

Mitchell, A. M., and Mitchell, T. J. (2010). Streptococcus pneumoniae: virulence factors and variation. Clin. Microbiol. Infect. 16, 411-418. doi: 10.1111/j.1469-0691.2010.03183.x

Moran, J. L., Graham, P. L., Rockliff, S., and Bersten, A. D. (2010). Updating the evidence for the role of corticosteroids in severe sepsis and septic shock: a Bayesian meta-analytic perspective. Crit. Care 14:R134. doi: 10.1186/ cc9182

Musher, D. M. (2016). Resistance of Streptococcus pneumoniae to Beta-Lactam Antibiotics, ed D. J. Sexton. UpToDate. Available online at: https://www. uptodate.com/contents/resistance-of-streptococcus-pneumoniae-to-betalactam-antibiotics

Nasa, P., Juneja, D., and Singh, O. (2012). Severe sepsis and septic shock in the elderly: an overview. World J. Crit. Care Med. 1, 23-30. doi: $10.5492 /$ wjccm.v1.i1.23

Ndjom, C. G., and Jones, H. P. (2015). CRH promotes S. pneumoniae growth in vitro and increases lung carriage in mice. Front. Microbiol. 6:279. doi: $10.3389 /$ fmicb. 2015.00279

Nezi, M., Mastorakos, G., Mouslech, Z. (2015). “Corticotropin releasing hormone and the immune/inflammatory response," in Endotext [Internet], eds L. J., De Groot, G. Chrousos, K. Dungan et al. (South Dartmouth: MDText.com, Inc.).

Page, D. B., Donnelly, J. P., and Wang, H. E. (2015). Community-, healthcare-, and hospital-acquired severe sepsis hospitalizations in the university healthsystem consortium. Crit. Care Med. 43, 1945-1951. doi: 10.1097/CCM.0000000000001164

Prigent, H., Maxime, V., and Annane, D. (2004). Clinical review: corticotherapy in sepsis. Crit. Care 8, 122-129. doi: 10.1186/cc2374

Procaccini, C., Pucino, V., De Rosa, V., Marone, G., and Matarese, G. (2014). Neuro-endocrine networks controlling immune system in health and disease. Front. Immunol. 5:143. doi: 10.3389/fimmu.2014.00143

Rappleye, E. (2015). Average Cost Per Inpatient Day Across 50 States [Online]. Beckker's Hospital Review. Available online at: http://www. beckershospitalreview.com/finance/average-cost-per-inpatient-day-across50-states.html

Rayner, C. F., Jackson, A. D., Rutman, A., Dewar, A., Mitchell, T. J., Andrew, P. W., et al. (1995). Interaction of pneumolysin-sufficient and -deficient isogenic variants of Streptococcus pneumoniae with human respiratory mucosa. Infect. Immun. 63, 442-447.

Riyaz, M., Manuel, R., and Joseph., N, K. (2014). Importance of serum procalcitonin in febrile neutropenia. J. Evol. Med. Dental Sci. 3, 8012-8018. doi: 10.14260/jemds/2014/3004

Rogers, P. D., Liu, T. T., Barker, K. S., Hilliard, G. M., English, B. K., Thornton, J., et al. (2007). Gene expression profiling of the response of Streptococcus pneumoniae to penicillin. J. Antimicrob. Chemother. 59, 616-626. doi: $10.1093 / \mathrm{jac} / \mathrm{dkl} 560$

Rogers, H. J., Perkins, H. R., and Ward, J. B. (1980). "Formation of cell wall polymers," in Microbial Cell Wall and Membranes, ed C. Nombela (London: Chapman \& Hall), 437-460.

Russell, J. A. (2006). Management of sepsis. New Engl. J. Med. 355, 1699-1713. doi: 10.1056/NEJMra043632

Sam, S., Corbridge, T. C., Mokhlesi, B., Comellas, A. P., and Molitch, M. E. (2004). Cortisol levels and mortality in severe sepsis. Clin. Endocrinol. 60, 29-35. doi: 10.1111/j.1365-2265.2004.01923.x

Sanchez, C. J., Kumar, N., Lizcano, A., Shivshankar, P., Dunning Hotopp, J. C., Jorgensen, J. H., et al. (2011). Streptococcus pneumoniae in biofilms are unable to cause invasive disease due to altered virulence determinant production. PLoS ONE 6:e28738. doi: 10.1371/journal.pone.0028738

Sandrini, S., Alghofaili, F., Freestone, P., and Yesilkaya, H. (2014). Host stress hormone norepinephrine stimulates pneumococcal growth, biofilm formation and virulence gene expression. BMC Microbiol. 14:180. doi: 10.1186/1471-2180-14-180

Schrag, S. J., McGee, L., Whitney, C. G., Beall, B., Craig, A. S., Choate, M. E., et al. (2004). Emergence of Streptococcus pneumoniae with very-highlevel resistance to penicillin. Antimicrob. Agents Chemother. 48, 3016-3023. doi: 10.1128/AAC.48.8.3016-3023.2004
Selinger, D. S., Selinger, R. C., and Reed, W. P. (1979). Resistance to infection of the external eye: the role of tears. Surv. Ophthalmol. 24, 33-38. doi: 10.1016/0039-6257(79)90145-0

Severin, A., Figueiredo, A. M., and Tomasz, A. (1996). Separation of abnormal cell wall composition from penicillin resistance through genetic transformation of Streptococcus pneumoniae. J. Bacteriol. 178, 1788-1792. doi: 10.1128/jb.178.7.1788-1792.1996

Silverman, M. N., Pearce, B. D., Biron, C. A., and Miller, A. H. (2005). Immune modulation of the hypothalamic-pituitary-adrenal (HPA) axis during viral infection. Viral Immunol. 18, 41-78. doi: 10.1089/vim.2005.18.41

Simard, M., Hill, L. A., Underhill, C. M., Keller, B. O., Villanueva, I., Hancock, R. E., et al. (2014). Pseudomonas aeruginosa elastase disrupts the cortisol-binding activity of corticosteroid-binding globulin. Endocrinology 155, 2900-2908. doi: 10.1210/en.2014-1055

Sligl, W. I., Milner, D. A. Jr., Sundar, S., Mphatswe, W., and Majumdar, S. R. (2009). Safety and efficacy of corticosteroids for the treatment of septic shock: a systematic review and meta-analysis. Clin. Infect. Dis. 49, 93-101. doi: $10.1086 / 599343$

ThyagaRajan, S., and Priyanka, H. P. (2012). Bidirectional communication between the neuroendocrine system and the immune system: relevance to health and diseases. Ann. Neurosci. 19, 40-46. doi: 10.5214/ans.0972.7531. 180410

van Selm, S., van Cann, L. M., Kolkman, M. A. B., van der Zeijst, B. A. M., and van Putten, J. P. M. (2003). Genetic basis for the structural difference between Streptococcus pneumoniae serotype 15B and 15C capsular polysaccharides. Infect. Immun. 71, 6192-6198. doi: 10.1128/IAI.71.11.6192-61 98.2003

van Tol, E. A., Petrusz, P., Lund, P. K., Yamauchi, M., and Sartor, R. B. (1996). Local production of corticotropin releasing hormone is increased in experimental intestinal inflammation in rats. Gut 39, 385-392. doi: 10.1136/gut.39.3.385

Verbrugghe, E., Boyen, F., Van Parys, A., Van Deun, K., Croubels, S., Thompson, A., et al. (2011). Stress induced Salmonella Typhimurium recrudescence in pigs coincides with cortisol induced increased intracellular proliferation in macrophages. Vet. Res. 42:118. doi: 10.1186/1297-9716-42-118

Volbeda, M., Wetterslev, J., Gluud, C., Zijlstra, J. G., van der Horst, I. C., and Keus, F. (2015). Glucocorticosteroids for sepsis: systematic review with metaanalysis and trial sequential analysis. Intensive Care Med. 41, 1220-1234. doi: 10.1007/s00134-015-3899-6

Weinberger, D. M., Trzcinski, K., Lu, Y. J., Bogaert, D., Brandes, A., Galagan, J., et al. (2009). Pneumococcal capsular polysaccharide structure predicts serotype prevalence. PLoS Pathog. 5:e1000476. doi: 10.1371/journal.ppat.1000476

Weiser, J. N., Bae, D., Epino, H., Gordon, S. B., Kapoor, M., Zenewicz, L. A., et al. (2001). Changes in availability of oxygen accentuate differences in capsular polysaccharide expression by phenotypic variants and clinical isolates of Streptococcus pneumoniae. Infect. Immun. 69, 5430-5439. doi: 10.1128/IAI.69.9.5430-5439.2001

Wilson, J. W., Schurr, M. J., LeBlanc, C. L., Ramamurthy, R., Buchanan, K. L., and Nickerson, C. A. (2002). Mechanisms of bacterial pathogenicity. Postgrad. Med. J. 78, 216-224. doi: 10.1136/pmj.78.918.216

Wilson, M., Seymour, R., and Henderson, B. (1998). Bacterial perturbation of cytokine networks. Infect. Immun. 66, 2401-2409.

Won, W. D., and Ross, H. C. (1975). Catecholamine and phagocytic responses in infected mice exposed to hyperbaric helium-oxygen atmospheres. Aviat. Space Environ. Med. 46, 191-193.

Wood, K. A., and Angus, D. C. (2004). Pharmacoeconomic implications of new therapies in sepsis. Pharmacoeconomics 22, 895-906. doi: 10.2165/00019053-200422140-00001

Conflict of Interest Statement: The authors declare that the research was conducted in the absence of any commercial or financial relationships that could be construed as a potential conflict of interest.

Copyright (c) 2017 Ngo Ndjom, Kantor and Jones. This is an open-access article distributed under the terms of the Creative Commons Attribution License (CC BY). The use, distribution or reproduction in other forums is permitted, provided the original author(s) or licensor are credited and that the original publication in this journal is cited, in accordance with accepted academic practice. No use, distribution or reproduction is permitted which does not comply with these terms. 